\title{
The design of health promotion strategies for seafarers
}

\author{
Tim Carter $^{1}$, Kimberly Karlshoej ${ }^{2}$ \\ ${ }^{1}$ Norwegian Centre for Maritime Medicine, Haukeland University Hospital, Bergen, Norway \\ 'Seafarers' Trust, ITF House, SE1 1DR, London, United Kingdom
}

\begin{abstract}
Health promoting interventions among seafarers have, to date, been limited in scope and their effectiveness is questionable. There is good knowledge base from a wide range of onshore settings that indicates how best to structure health promotion initiatives in ways that are accepted by those affected by them and where their effectiveness has been fully evaluated.

Here we identify the main lessons to be learnt from experience in other sectors and note the special features of the settings in which seafarers live and work as the basis for strategic development. The history of health promoting initiatives in seafarers is also summarised.

The aim of this review is to foster debate about the best means to formulate seafarer health promotion initiatives and to introduce them in such ways that their effectiveness can be evaluated. The review has its origins as a scoping document for a strategic review of seafarer health promotion supported by the Seafarers' Trust.
\end{abstract}

(Int Marit Health 2017; 68, 2: 102-107)

Key words: health promotion, health education, seafarer, arterial disease, musculoskeletal disease

\section{INTRODUCTION}

There have been a number of initiatives to improve the health of seafarers by means of health-promoting interventions. One of the greatest challenges has been how to deliver interventions to a mobile and often isolated group who spend a part of each year at sea, in port and at home on leave. Most initiatives have focused on awareness and education, few have sought to change behaviour patterns or to improve the opportunities for maintaining and improving health on board or ashore [1, 2]. To date such initiatives have usually been developed piecemeal and have rarely include arrangements for evaluating their effectiveness. They have not taken advantage of onshore experience in health promotion, where there is now a good evidence base. This evidence base has enabled theories and models to be derived that have proven utility when planning interventions in new settings.

The maritime sector needs to learn to develop health promotion strategies that use the lessons from well designed and evaluated interventions in other settings and formulate approaches based on such experience. The impetus for this review, which was commissioned from the first author by the ITF Seafarers' Trust, comes from the Trust's wish to have a strategic framework in place that enables them to encourage and support the development of sound approaches to health promotion for seafarers [3].

Three questions need addressing when developing a strategy on health promotion for seafarers. They need to be considered from several perspectives, those of the seafarer whose health is at issue, those of the shipowner who is responsible for working and living conditions on board, and those of the health professional who is aware of patterns of health and disease and of the validity of different approaches to health promoting interventions:

What matters?

- Risks to seafarer health: their frequency, severity, variability and timeline.

What works?

- Available forms of intervention: their relevance, deliverability, effectiveness and timeline. 
Who cares?

- Aspirations of seafarers for better health and wellbeing.

- Importance attached to better seafarer health by those able to support maritime health promotion interventions. Collaboration between seafarers and their representatives, shipowners and health professionals is essential to define answers. Each will be able to make complementary contributions. The answers to the questions 'what matters?' and 'what works?' have both scientific and attitudinal components and it is usually best to start with a well-defined assessment of the scale of risk and the validity of options for intervention. 'Who cares?' is a socio-political issue, but one that will determine whether any initiative has a hope of being successful. The outcome of this collaborative process can form the basis for decisions on how best to shape enhanced seafarer health promotion initiatives.

\section{WHAT IS HEALTH PROMOTION?}

Health promotion has been defined by the World Health Organisation's (WHO) 2005 Bangkok Charter for Health Promotion in a Globalised World as "the process of enabling people to increase control over their health and its determinants, and thereby improve their health" [4].

A key feature of this definition is that people participating in health promotion activities have a feeling of personal ownership for them. Externally imposed interventions that are not owned by participants have a small chance of being successful, especially if they rely in inducing behaviour change in participants.

Health promotion as defined by WHO includes health education to improve knowledge about how people may improve their health. This has been the core of most seafarer interventions to date. Education is, however, only one component, others are:

- Securing health promoting behaviour changes at either the individual level based on personal risk factors (e.g. weight management, smoking cessation), or more commonly including the whole target population (e.g. exercise);

- Development of health promoting support networks between members of the target group, but also including those they interact with (e.g. seafarer peer group initiatives on health such as exercise targets, family members' engagement in diet and exercise programmes during leave periods);

- Provision of measures that assist the group in developing and maintaining health promoting behaviours (e.g. development and training of seafarer peer group health educators, provision of suitable food on board for those seeking to reduce calorie intake, provision of on board exercise equipment and recreational facilities, arrangements for sporting events when ashore);

- Environmental/working condition modification to reduce risks to health (e.g. avoidance of exposure to hazardous working conditions, management of working hours to avoid fatigue);

- Empowerment of participants to help them secure support networks on board and ashore, ensure provision of the items such as exercise facilities and healthy food options when on board and a voice on the management of health risks from maritime working and living conditions. The need for empowerment is often given a low profile in workplace based health promotion initiatives as it can be seen as disrupting employer/employee relationships. Fear of empowerment can result in health promotion being limited to health educational initiatives which are ineffective because they do not address the importance of modifying social and environmental factors in ways that will encourage health promoting behaviours and thus minimise ill-health and improve perceived wellbeing.

Many techniques can be used to promote health. These include awareness and publicity campaigns, using a range of media. Personal contacts are important; these may take place during clinical consultations, such as seafarer medical examinations. Personal contacts may also form part of a health promotion initiative to assist participants to understand risks or to undertake or assert the need for preventative measures. Group interactions can also play a major role in securing behaviour change and in developing support networks to maintain health-promoting behaviours.

The contribution of these techniques to each of the components of health promotion, as listed above has been analysed, based on experience ashore. This has enabled explanatory and prescriptive models to be derived to assist with programme planning in new and existing settings $[5,6]$.

In practice health promotion initiatives have often been framed in terms of the control of a specific risk to health in a target population. The focus may either be on the control of one particular risk factor, such as diet or smoking, or on one particular disease or disease group, such as arterial disease or cancer. In the shorter term similar approaches may be used to improve food hygiene or to prevent transmission of an infectious disease. However, there is now a growing recognition that interventions that integrate all aspects of the health of the target group and which aim to develop healthy overall lifestyle, rather than to prevent a specific condition, may be more acceptable and effective than those targeting a single risk or condition [7]. They may also make a more positive contribution to a person's sense of wellbeing.

\section{WHAT FEATURES OF SEAFARING LIFE AND WORK ARE RELEVANT TO HEALTH PROMOTION?}

Serving seafarers are a selected group of the population: they have self-selected into the profession; they have been 
selected by an employer, and have also had their medical fitness to work at sea assessed. They are also a survivor group, in that all the selective factors that apply at entry continue to apply throughout their working lives. Thus they could be expected to be fitter and to have a different pattern of health risks from those in the general population. By contrast, illness may be more prevalent in those who have recently ceased to work at sea as it is one of the reasons for leaving the industry.

The recruitment of seafarers is now global, with the majority coming from Asia and in particular the Philippines. Seafarers are prone to similar patterns of disease to those found in the populations they come from. They are will also share their beliefs about health with their home population. However, living and working at sea present their own profession-specific risks. These may include lack of access to the diet of choice, scope for exposure to infections not present in their home country, occupational risks from exposure to hazardous agents and mental distress from job demands and isolation.

Health promotion initiatives need to be delivered to the target population and the pattern of work for seafarers can make this difficult, except where the target is to prevent short term risks on board, such as food borne infections. There are in three different settings in which most serving seafarers, apart from those on very local coastal shipping, can be found:

- On board, perhaps for $50-80 \%$ of the year.

- In port but away from home for $0-10 \%$ of the year.

- On leave for the balance of $10-50 \%$ of the year.

This means that an intervention aimed at weight control that is organised on board will only be effective if calorie intake is also controlled during leave. Similarly an initiative offering confidential counselling to reduce problems from mental distress can be hard to deliver on board because of fears about confidentiality, feasible in major ports but only if the vessel is there for long enough and time ashore is available. Counselling during leave may only be available as part of the general health care system ashore and will not be tailored to the particular problems of working and living at sea.

\section{WHAT IS THE HISTORY OF HEALTH PROMOTING INTERVENTIONS IN SEAFARERS?}

In the nineteenth century the main areas of health concern were nutritional deficiencies, infectious diseases and the risks from alcohol and venereal diseases. Advice on how to minimise risks to crewmembers from the latter when in foreign ports was given to ship captains, while much of the effort to develop missions and sailors' homes onshore was an attempt to provide morally acceptable alternatives to the culture of sailortown boarding houses where alcohol and sexual services were commonly available $[8,9]$.
In the first part of the twentieth century, these problems remained. There was sometimes tension between those taking moral stand, who considered that casual sex must be condemned and that seafarers got their just deserts if they contracted venereal disease, and the more pragmatic physicians who favoured easy access to preventative measures such as condoms as they recognised the inevitability of casual sex while seafarers were in port, and had experience of the ineffectiveness of treatment and the distress caused by these diseases.

However, during this period it was the poor accommodation on board and its effects on the incidence of diseases such as tuberculosis that gained most attention. As with scurvy from adulterated lemon juice in earlier times, the answers lay in the hands of ship operators, with a poorly organised population of seafarers unable to be sufficiently assertive to ensure that their health was protected. Improvements were slow to come as they depended on a new generation of ships being built that had more generous and more hygienic crew accommodation.

A range of measures to prevent infections: vaccinations, avoiding contaminated food when ashore, protection from mosquito bites, prophylaxis for malaria and $\mathrm{X}$ rays to detect early tuberculosis formed the core of health protection initiatives in the mid twentieth century. Some depended on the seafarer, some on ship operators. However, during this time the incidence of infections declined and different diseases became the main causes of mortality and early retirement in seafarers. Among these, arterial disease (heart attacks and stroke) and cancers (especially of the lung and skin) predominated. Most of these conditions had multiple risk factors that contributed to the development of disease over ten or more years. These risk factors were progressively identified in the 1960s to 1980 s, but little attention was given to the prevention of diseases associated with them in seafarers at the time. This was in part because infection risks were still seen as the major seafarer health problem but also because the risk factors for non-infectious diseases were multiple and closely linked to lifestyle choices such as smoking, diet and exercise. Here there was often a lack of enthusiasm for action that was shared by seafarers and ship operators.

A notable gap in the historical record relates to mental health problems in seafarers, apart from concern during the Second World War about psychological consequences of the fear and reality of ships being sunk by enemy action, they appeared to go unrecorded, despite their likely frequency.

Throughout history information on the health of merchant seafarers and even on their causes of death has been limited and of uncertain quality. This has reduced the credibility of those trying to make the case for improvements in health. It has also enabled those who feel economically 
threatened by the actions required to improve seafarer health, such as better food and accommodation, to argue that there is no health-based justification for improvement.

Since 2000 there have been interventions aimed at these chronic disease risk factors, such as the Seafarers Health Intervention Programme (SHIP) of ICSW/ISWAN, the provision of exercise facilities at sea and opportunities for sport in port $[1,10]$. There have also been recommendations that doctors encourage health promoting behaviour changes in the course of seafarer medical examinations [11].

\section{WHAT LESSONS CAN BE LEARNT FROM THIS HISTORY?}

The lack of reliable information on the health of merchant seafarers remains a continuing problem as does the neglect of certain conditions, such as mental ill-health [12]. There are few epidemiological studies and none of these relate to the major crewing nations of Asia. Ship operators, employers and their insurers also hold information, but it is not generally accessible as it is regarded as being commercially confidential to the holder. It is possible to extrapolate information on disease risks from other sources, for instance from related working populations such as the military and those in the offshore energy sector. General population data may be used, especially to identify disease patterns in particular ethnic groups, but extrapolation from such data may not give a valid estimate for seafarers because of their unique pattern of professional selection and remote working conditions.

The moral overlays that were associated with managing drunkenness and debauchery in the nineteenth century were of their time and have little place now. Infections remain a continuing but relatively small risk, with immunisation, prophylactics for malaria and well established food hygiene practices the most important preventative measures that need to be in place. These risks are characterised by a short interval between exposure to the risk and the onset of disease. Hence there are incentives for ship operators and employers to manage the risks effectively, as prevention is likely to be beneficial within the duration of a single voyage or contract of employment.

However, for the biggest current disease risks such as those of arterial disease, type 2 diabetes and cancers the situation is different. Disease follows many years of exposure to risks, many of which are linked to lifestyle, and so is likely to arise late in a seafarer's career. Casual employment means that the ship operator and employer may have few incentives and may even court crew unpopularity by adopting coercive approaches to risks such as weight control/ diet and smoking among seafarers early in their careers.

As a consequence it may be that securing behaviour change in the seafarer and ensuring that there is peer sup- port for this is likely to be the best approach for long-term problems that are not associated with job demands or hazardous working conditions. The ship operator or employer would then have an important enabling role, for instance by ensuring that a palatable and interesting low-calorie diet is available for those who need it, while healthy food options are available to all, as well as by banning or severely restricting opportunities for smoking.

\section{WHAT ARE THE MOTIVES FOR IMPROVING THE HEALTH OF SEAFARERS?}

All those engaged in the health of seafarers state that they wish to play their part in improving it. However, priorities differ in terms of the relative importance of short and long-term health problems, as well as between those illnesses attributable to working or living conditions at sea and those that occur with similar frequencies in the general population and in seafarers. Different interest groups also have different concerns about the economic consequences of ill health in seafarers.

Seafarers can be expected to have an interest in living a long and healthy life. The pattern of working and living at sea, as well as the opportunity to feel that leave is a time to treat yourself, does however mean that many adopt lifestyles that lay the ground for long-term ill health. A number of more short-term risks, such as dental care and the prevention of infection are usually, but not always, better managed than the lifestyle associated risk factors for conditions that arise later in life.

Employers would like to have healthy and efficient crews but they may tend, in the current pattern of short-term crew contracts, not to see the prevention of long-term risks as important, nor do they wish to adopt coercive approaches to prevention. A few do have positive and potentially coercive health and fitness promoting policies, such as the requirement for periodic fitness and capability testing for all their crews, but with provisions for remedial measures should a crewmember not meet the required criteria.

When there are clear safety or performance benefits in the short term there is a far greater incentive for action, both for the individual and for their employer. For instance the introduction of refresher training every 5 years on the essential safety courses required under the International Maritime Organisation Standards of Training, Certification and Watchkeeping Convention (STCW) as amended in 2010 now means that a measure of physical fitness and capability has to be demonstrated if a person's career is to continue. Maintaining the required standards of physical fitness to succeed in these courses could have incidental benefits in terms of reducing the risk of arterial disease and type 2 diabetes.

Maritime insurers, including the P \& I Clubs, share the employers' interest in crew health and have led in some 
recent health education initiatives, but their main focus is on exclusion of those who they consider may present risks from ill-health while under contract as they are seen as more likely to require costly medical treatment and repatriation for which the insurer will be liable.

Maritime regulatory authorities have responsibilities under the Maritime Labour Convention, 2006 and other conventions to introduce regulations aimed at maintaining certain aspects of health and wellbeing in seafarers on ships that are registered with them.

A range of organisations and groups that are concerned with seafarer health and wellbeing all have their own, often partially self-serving, perspectives on health promotion. These include the seafarer missions, port welfare service providers and maritime doctors.

\section{WHAT IS THE PATTERN OF HEALTH/ /WELLBEING RISKS IN SEAFARERS?}

Despite the lack of an extensive knowledge base on seafarer health the available information indicates that the predominant causes of serious illness and death in seafarers are broadly similar to those in the same socioeconomic group in their country of residence. The most common causes are the arterial diseases and cancers.

Widespread but non-fatal conditions include musculoskeletal pain, often with limitation of movement, and psychological distress as well as other forms of mental ill-health which can be disabling for the individual and may lead to early termination of a career at sea. Musculoskeletal and psychological problems may be attributable to personal factors, to duties and job demands on board or to a combination of both.

Other significant contributors are occupational diseases and accidents. These will not be considered further here, as there are well defined frameworks for the management of these risks that ship operators are required or recommended to follow.

In addition, the harm from several other risks, such of those from hot and cold climates, from sexually transmitted infections, including HIV, and from exposure to food, water and disease vectors while in port are all largely preventable.

\section{WHAT ARE THE HEALTH AND WELLBEING ISSUES FOR SEAFARERS THAT COULD BE ADDRESSED BY HEALTH PROMOTING INTERVENTIONS?}

Most forms of arterial disease, many cancers, the bulk of musculoskeletal disease and the commoner types of psychological distress are all amenable to preventative interventions delivered using approaches that are widely used ashore.

Conditions that have an evidence base that can be used to justify and shape intervention include:
1. Arterial disease: smoking, diet/obesity, exercise with additional clinical interventions to identify and treat high blood pressure, raised blood lipid levels and diabetes.

2. Cancers: lung and several other cancers have smoking as a causal factor - should there be concurrent or past asbestos exposure this effect is multiplied, sun exposure increases the risk of skin cancer, dietary components can contribute to bowel cancers.

3. Musculoskeletal disease: regular training to improve fitness can reduce risks and rapid mobilisation after some conditions such as low back pain can reduce long term disability. There is a parallel need for sound systems of work to ensure that musculoskeletal demands from routine duties do not exceed accepted weight, reach or frequency criteria.

4. Psychological distress: improved understanding of the effects of personal crises and overload or boredom at while at sea, with acceptance that such effects occur and are best talked through can ameliorate distress. Specialised social networking sites for those in distress, supported by online or face-to-face counselling are promising developments. Port welfare providers may also have a role.

\section{WHAT IS THE EVIDENCE BASE ON THE EFFECTIVENESS OF HEALTH PROMOTING APPROACHES?}

The evidence base for the success of health promoting interventions in seafarers is very limited. A number of aspects can be evaluated:

1. Distribution or access to materials used in the programme.

2. Awareness of the intervention programme, both in the direct target group and those who need to support the group, including family members during periods of leave.

3. Intentions to change behaviour or to provide the support services required to help individual participants.

4. Actual behavioural change, its speed of uptake, the proportion of those targeted who are complying, the persistence of the change.

5. Maintaining behaviour changes as measured by secondary markers such as weight, smoking habit, participation in exercise programmes.

6. Effectiveness of the programme in terms of primary markers: disease incidence, disability, loss of employment, death.

All these markers of the effectiveness of interventions have been used to evaluate the effectiveness of health promotion initiatives on shore and their results have the potential to be extrapolated to seafaring populations. 


\section{CONCLUSIONS}

1. Interventions to promote seafarer health have a long history but have been poorly co-ordinated and their effectiveness has not been established.

2. There has been little or no interaction between those developing seafarer initiatives and those with onshore expertise in health promotion.

3. There is a large amount of knowledge and experience about onshore health promotion theory and practice that is applicable to seafarers and could be useful in the development of future interventions.

4. The pattern of work and life at sea and on leave, the global recruitment of seafarers and the structure of employment in the sector pose challenges to successful implementation of health promoting initiatives.

5. Points 1-4 need to be considered and addressed by those with relevant expertise in order to improve the promotion of seafarer health and wellbeing in the future.

6. The right mix of specialist expertise coupled with commitment from those who have responsibilities for the employment of seafarers needs to be harnessed to produce a widely accepted set of priorities for action and for the delivery of programmes based on them.

\section{ACKNOWLEDGEMENTS}

This article is based on work funded by the Seafarers' Trust. Tim Carter was contracted to prepare a background document for a Seafarers' Trust expert workshop on health promotion held in November 2016. Kimberly Karlshoej is the head of the Seafarers' Trust.

\section{REFERENCES}

1. Seafarers' Health Information Programme, International Seafarers' Welfare and Assistance Network. http://seafarerswelfare.org/what -we-do/projects/ship (accessed 20 January 2017).

2. Healthy Living at Sea, Videotel. Release in 2017. This is a series of ten videos covering different aspects of seafarer health. http:// videotel.com(Videotel home page, accessed 20 January 2017).

3. ITF Seafarers Trust. http://www.seafarerstrust.org (accessed 20 January 2017).

4. The Bangkok Charter for Health Promotion in a Globalized World. www.who.int (accessed 3 November 2015).

5. Davies M, Macdowall W. (Editors). Health Promotion Theory. OUP, Maidenhead 2006.

6. Macdowall W. (Editors). Health Promotion Practice. OUP, Maidenhead 2006

7. Macdowall W. Personal communication 2016.

8. Leach H. The Ship Captain's Medical Guide. 2nd Edition. Simkin Marshall, London 1868: 7-8.

9. Carter T. Merchant Seamen's Health 1860-1960: medicine, technology, shipowners and the state in Britain. Woodbridge, Boydell Press. 2014. pp. 68-77. Note: information on other historical aspects of seafarer health promotion in UK can be found in this book.

10. Training on Board. International Seafarers' Welfare and Assistance Network . http://seafarerswelfare.org/what-we-do/projects/training-on-board(accessed 20 January 2017).

11. Guidelines on the medical examinations of seafarers. International Labour Office, International Maritime Organization. Geneva: ILO, 2013. p.21.

12. Carter T. Mapping the knowledge base for maritime health: 3 illness and injury in seafarers. Int Marit Health. 2011; 62(4): 224-240, indexed in Pubmed: 22544497. 